\title{
Traumatic brain injury in young children: Postacute effects on cognitive and school readiness skills
}

\author{
H. GERRY TAYLOR, ${ }^{1}$ MAEGAN D. SWARTWOUT, ${ }^{2}$ KEITH OWEN YEATES, ${ }^{3}$ \\ NICOLAY CHERTKOFF WALZ, ${ }^{4}$ TERRY STANCIN,${ }^{5}$ AND SHARI L. WADE ${ }^{6}$ \\ ${ }^{1}$ Division of Developmental and Behavioral Pediatrics and Pediatric Psychology, Department of Pediatrics, \\ Case Western Reserve University and University Hospitals Case Medical Center, Cleveland, Ohio \\ ${ }^{2}$ Department of Psychology, University of Houston, Houston, Texas \\ ${ }^{3}$ Division of Psychology, Department of Pediatrics, The Ohio State University \& Center for Biobehavioral Health, \\ The Research Institute at Nationwide Children's Hospital, Columbus, Ohio \\ ${ }^{4}$ Division of Behavioral Medicine and Clinical Psychology, Department of Pediatrics, Cincinnati Children's Hospital Medical \\ Center and University of Cincinnati College of Medicine, Cincinnati, Ohio \\ ${ }^{5}$ Division of Pediatric Psychology, Department of Pediatrics, MetroHealth Medical Center and Case Western Reserve University \\ School of Medicine, Cleveland, Ohio \\ ${ }^{6}$ Department of Rehabilitation, Cincinnati Children's Hospital Medical Center and University of Cincinnati College of Medicine, \\ Cincinnati, Ohio
}

(Received March 25, 2008; Final Revision June 12, 2008; AcCePted June 13, 2008)

\begin{abstract}
Previous studies have documented weaknesses in cognitive ability and early academic readiness in young children with traumatic brain injury (TBI). However, few of these studies have rigorously controlled for demographic characteristics, examined the effects of TBI severity on a wide range of skills, or explored moderating influences of environmental factors on outcomes. To meet these objectives, each of three groups of children with TBI (20 with severe, 64 with moderate, and 15 with mild) were compared with a group of 117 children with orthopedic injuries (OI group). The children were hospitalized for their injuries between 3 and 6 years of age and were assessed an average of $1 \frac{1}{2}$ months post injury. Analysis revealed generalized weaknesses in cognitive and school readiness skills in the severe TBI group and less pervasive effects of moderate TBI. Indices of TBI severity predicted outcomes within the TBI sample and environmental factors moderated the effects of TBI on some measures. The findings document adverse effects of TBI in early childhood on postacute cognitive and school readiness skills and indicate that these effects are related to both injury severity and the family environment. (JINS, 2008, 14, 734-745.)
\end{abstract}

Keywords: Child, Preschool, Brain injuries, Neurobehavior manifestations, Outcome, Moderator variables

\section{INTRODUCTION}

Traumatic brain injury (TBI) is one of the most common causes of death and long-term disability in the pediatric age range (Gotschall, 1993; Kraus, 1995). According to a report on emergency department (ED) visits, hospitalizations, and deaths in the United States for the years 1995-2001 (Langlois et al., 2006), nearly half a million children $0-14$ years of age had TBI each year during this period. Among survivors, the consequences of TBI in children include physical

Correspondence and reprint requests to: H. Gerry Taylor, Division of Developmental/Behavioral Pediatrics and Psychology, D.O. Walker Building, Suite 3150, 10524 Euclid Avenue, Cleveland, OH. E-mail: hgt2@ case.edu conditions (e.g., neuromotor impairment, seizures, traumarelated orthopedic injuries), lowered cognitive and academic skills relative to age expectations or preinjury estimates, and problems in school performance, behavior, socialization, and adaptive functioning (Anderson et al., 2006; Ewing-Cobbs et al., 2004a; Schwartz et al., 2003; Stancin et al., 2002; Yeates, 2000; Yeates \& Taylor, 1997). Although TBI in school-age children is associated with global cognitive deficits (Anderson et al., 2006; Ewing-Cobbs et al., 2004b; Fay et al., 1994; Levin et al., 1995; Taylor et al., 1999; Yeates, 2000), impairments are especially pronounced on measures of memory, perceptual abilities and psychomotor speed, attention and executive function, and discourse processing (Anderson \& Catroppa, 2005; Bawden 
et al., 1985; Chadwick et al., 1981; Dennis \& Barnes, 2001; Donders, 2001; Donders \& Giroux, 2005; Ewing-Cobbs \& Barnes, 2002; Levin \& Hanten, 2005; Taylor et al., 1999).

More negative outcomes are predicted by increasing TBI severity and less advantaged family environments (Anderson et al., 2006; Fletcher et al., 1995; Schwartz et al., 2003; Taylor et al., 1999, 2002). Whereas cognitive deficits are well documented in school-age children with moderate to severe TBI (Anderson et al., 2004, 2006, 2005b; Taylor et al., 1999), studies of children with mild TBI have yielded inconsistent findings. Some of these studies have demonstrated only transient cognitive deficits if any and others have suggested emerging consequences over time after injury (Anderson et al., 2001; Gronwall et al., 1997; Keenan et al., 2007; Ponsford et al., 1999).

Younger age at injury is another predictor of worse outcomes. Specifically, children aged 2 to 7 years at the time of injury are more susceptible to deficits in expressive language, attention, and academic achievement compared with children injured at later ages (Anderson et al., 2005a; Barnes et al., 1999; Dennis et al., 1995; Ewing-Cobbs \& Barnes, 2002; Ewing-Cobbs et al., 1989, 1997; Morse et al., 1999; Verger et al., 2000). Researchers have speculated that the poorer outcomes in younger children may reflect a greater susceptibility to diffuse brain insult or abnormalities in neurogenesis, or a greater effect of injury on postinjury skill development (Anderson \& Moore, 1995; Barnes et al., 1999; Ewing-Cobbs et al., 1997, 2004b; Taylor \& Alden, 1997; Wetherington \& Hooper, 2006).

Unfortunately, questions remain regarding the nature of the effects on TBI in young children on cognition and achievement. Previous research demonstrates both postacute and persisting effects of TBI in this age group on a wide range of ability measures (Anderson et al., 1999, 2000a,b, 2004, 2006; Ewing-Cobbs et al., 1989, 1997, 2004b; Gronwall et al., 1997). However, methodological limitations make it difficult to interpret these findings, as past studies have either failed to include a comparison group of children without TBI or have used uninjured children as controls. Inclusion of controls without TBI is needed to assess the effects of varying degrees of TBI severity relative to expectations for children without brain insult. But comparison with uninjured controls is also problematic. These children may have fewer preinjury developmental problems and come from more advantaged family backgrounds than children with TBI, raising questions as to whether group differences were present before TBI (Goldstrohm \& Arffa, 2005; Keenan et al., 2007).

Determining the postacute effects of TBI on cognitive and school readiness skills is especially critical given the need for early identification of children who have been adversely affected by injury. Awareness of postacute deficits would be useful in gauging children's needs for interventions as they are transitioning to school entry or beginning to acquire basic academic competences. Data suggesting persisting or even later-emerging impairments in this age group (Anderson et al., 1999, 2000b, 2004, 2006; Ewing-
Cobbs et al., 1989, 1997; Gronwall et al., 1997) further reinforce the importance of an awareness of postacute sequelae. A better understanding of the effects of TBI severity and environmental factors on outcomes would also be useful in identifying children at high risk for sequelae.

The primary objective of the present study was thus to investigate the effects of TBI in young children on postacute cognitive and achievement outcomes using methods that rigorously control for noninjury influences on outcomes. To provide an estimate of the effects of TBI that took into account preinjury risk exposure as well as the experience of hospitalization for injury, children admitted to hospitals for orthopedic injuries but without TBI were recruited as a comparison group. Outcomes were assessed using comprehensive measures of cognitive and early academic skills that were applicable across all or at least a major portion of the 3- to 6 -year-old age range. Previous findings suggesting that children's self-regulatory or executive functions may be vulnerable to TBI and may play an important role in children's ongoing development (Anderson et al., 2005b; Blair, 2002; Bronson, 2000; Ewing-Cobbs et al., 2004b) prompted inclusion of several experimental measures of this skill domain. Finally, group comparisons were made controlling for sociodemographic factors.

We hypothesized that young children hospitalized for TBI would have deficits in cognitive and school readiness skills relative to children with orthopedic injuries only, and that these deficits would be most pervasive in children with severe TBI. Given the failure of many previous studies to investigate a wide range of outcomes in young children with TBI, we anticipated wide-ranging deficits and did not have expectations with respect to which skills would be more or less affected. We also hypothesized that outcomes would be worse for children from more disadvantaged environments (Anderson et al., 2006), and we explored the possibility that such environments might even exacerbate the negative consequences of TBI (Taylor et al., 1999, 2002; Yeates et al., 1997).

\section{METHODS}

\section{Sample}

Children were recruited from consecutive inpatient admissions from 2003 to 2006 of children with TBI or with OI at three tertiary care children's hospitals and a general hospital, all of which had Level 1 trauma centers. The study was approved by the ethics boards of all participating hospitals and informed consent was obtained before participation. Eligibility criteria included age at injury between 3 years, 0 months and 6 years, 11 months, no documentation in the medical chart or in parent interview of child abuse as a cause of the injury, and English as the primary spoken language in the home. Children with a previous history of autism, mental retardation, or a neurological disorder were excluded. Eligibility for the TBI group included a TBI due 
to blunt trauma requiring overnight admission to the hospital and either a Glasgow Coma Scale (GCS; Teasdale \& Jennett, 1974) score $<15$, suggesting altered neurological status, or evidence for TBI-related brain abnormalities from computed tomography (CT) or magnetic resonance imaging (MRI).

Consistent with previous investigations (Anderson et al., 2006; Fletcher et al., 1990; Taylor et al., 1999), severe TBI was defined as one resulting in a GCS score of 8 or less. Moderate TBI was defined as a GCS score of 9-12 or a higher GCS score with abnormal neuroimaging. A final group of children with mild TBI comprised those participants with GCS scores of 13-14 without neuroimaging abnormalities. To insure that evidence for TBI was based on direct physical examination and not on history alone, children with GCS scores of 15 and normal neuroimaging were not recruited. The GCS score assigned to the child was the lowest one recorded. Inclusion in the OI group required a documented bone fracture in an area of the body other than the head that required an overnight hospital stay, and the absence of any evidence of loss of consciousness or other findings suggestive of brain injury.

A total of 221 children (102 with TBI and 119 with OI) and their caregivers were enrolled in the study. Recruitment rates for families contacted were somewhat higher for the combined TBI sample than for the OI group (53\% vs. 35\%). Examination of pre-enrollment screening data indicated that refusal rates were lower for children with the highest GCS scores. However, comparison of participants with nonparticipants on census-based neighborhood income failed to reveal differences for the sample as a whole or for subsets of children with GCS scores $<9,9-12$, or 13-14. At least a portion of the test battery was administered to 216 children (98\%) at the postacute assessment. The final sample com- prised 99 children with TBI (20 severe, 64 moderate, and 15 mild) and 117 with OI. Reasons for failure to test children included injuries that precluded testing ( 2 with severe TBI) and difficulties in arranging for travel for the assessment ( 1 with severe TBI and 2 with OI). Untested children did not differ from those assessed in parental marital status, neighborhood income, race, or sex.

As shown in Table 1, the groups did not differ statistically in age at assessment, neighborhood income, distributions of sex, race, and maternal education levels, or parent resources and stressors as measured by the Life Stressors and Social Resources Inventory-Adult Version (LISRES-A; Moos \& Moos, 1994). Data collected in parent interview also failed to suggest group differences in preinjury developmental status as assessed by special education services or prior concerns about the child's development, behavior, or learning. The educational classification of special services was not requested and in view of the young age of the sample we did not inquire about attention deficits or learning disorders.

Table 2 lists injury and medical characteristics for each of the groups. The time between injury and assessment was shorter for the OI group than for the TBI groups (significant for mild and moderate TBI groups, nonsignificant trend for severe TBI group). This difference was likely related to our willingness to extend recruitment somewhat beyond our initial recruitment window (3 months after injury) in an effort to enroll as many children with TBI as possible. The groups also differed in their mean New Injury Severity Score (NISS; Osler et al., 1997), defined as the sum of the squares of the Abbreviated Injury Scale (AIS) scores for each child's three most severely injured body regions. Post hoc tests indicated higher NISS for the severe and moderate TBI groups compared with the mild TBI and OI groups. The

Table 1. Sample demographic characteristics

\begin{tabular}{|c|c|c|c|c|}
\hline & \multicolumn{4}{|c|}{ Group } \\
\hline & $\begin{array}{l}\text { Severe TBI } \\
\quad(n=20)\end{array}$ & $\begin{array}{l}\text { Moderate TBI } \\
\quad(n=64)\end{array}$ & $\begin{array}{l}\text { Mild TBI } \\
(n=15)\end{array}$ & $\begin{array}{c}\text { OI } \\
(n=117)\end{array}$ \\
\hline Age at assessment in years, $\mathrm{M}(S D)$ & $4.86(0.88)$ & $5.19(1.20)$ & $4.68(1.00)$ & $5.21(1.08)$ \\
\hline Males, $n(\%)$ & $14(70 \%)$ & $37(58 \%)$ & $6(40 \%)$ & $67(57 \%)$ \\
\hline Non-white race, $n(\%)$ & $7(35 \%)$ & $22(34 \%)$ & $6(40 \%)$ & $27(23 \%)$ \\
\hline Census median family income in dollars, $\mathrm{M}(S D)$ & $52,767(16,435)$ & $57,096(26,539)$ & $51,556(25,874)$ & $63,888(23,410)$ \\
\hline \multicolumn{5}{|l|}{ Maternal education, $n(\%)$ : } \\
\hline$<2$ years high school & $0(0 \%)$ & $3(5 \%)$ & $0(0 \%)$ & $2(2 \%)$ \\
\hline 2 years high school & $5(25 \%)$ & $7(11 \%)$ & $1(7 \%)$ & $6(5 \%)$ \\
\hline High school degree/GED & $10(50 \%)$ & $24(38 \%)$ & $7(50 \%)$ & $45(38 \%)$ \\
\hline 2 years college & $4(20 \%)$ & $11(17 \%)$ & $3(21 \%)$ & $23(20 \%)$ \\
\hline 4 years college & $1(5 \%)$ & $12(19 \%)$ & $3(21 \%)$ & $29(25 \%)$ \\
\hline Graduate degree & $0 \quad(0 \%)$ & $6(10 \%)$ & $0 \quad(0 \%)$ & $12(10 \%)$ \\
\hline \multicolumn{5}{|l|}{ LISRES-A (T score) } \\
\hline Stressors, M (SD) & $49.65(6.87)$ & $47.85(5.97)$ & $50.02(5.66)$ & $47.48(5.93)$ \\
\hline Resources, M $(S D)$ & $49.49(7.88)$ & $51.99(6.41)$ & $50.03(5.69)$ & $51.71(5.37)$ \\
\hline
\end{tabular}

Note. $\mathrm{TBI}=$ traumatic brain injury; $\mathrm{OI}=$ orthopedic injury; $\mathrm{SD}=$ standard deviation; GED $=$ General Education Diploma. All group differences nonsignificant. LISRES-A = Life Stressors and Social Resources Inventory-Adult Version. 
Table 2. Injury and medical characteristics

\begin{tabular}{|c|c|c|c|c|}
\hline & \multicolumn{4}{|c|}{ Group } \\
\hline & $\begin{array}{l}\text { Severe TBI } \\
\quad(n=20)\end{array}$ & $\begin{array}{l}\text { Moderate TBI } \\
\quad(n=64)\end{array}$ & $\begin{array}{l}\text { Mild TBI } \\
(n=15)\end{array}$ & $\begin{array}{c}\text { OI } \\
(n=117)\end{array}$ \\
\hline Age at injury in years, mean $(S D)$ & $4.74(0.88)$ & $5.06(1.20)$ & $4.55(1.03)$ & $5.11(1.07)$ \\
\hline Time since injury in months, mean $(S D)^{*}$ & $1.51(0.75)$ & $1.51(0.76)$ & $1.62(0.82)$ & $1.16(0.50)$ \\
\hline \multicolumn{5}{|l|}{ External cause of injury, $n(\%): * a$} \\
\hline Transportation & $12(60 \%)$ & $22(34 \%)$ & $5(33 \%)$ & $10(9 \%)$ \\
\hline Bicycle crash & $0 \quad(0 \%)$ & $3(5 \%)$ & $1(7 \%)$ & $7(6 \%)$ \\
\hline Fall & $6(30 \%)$ & $33(52 \%)$ & $9(60 \%)$ & $84(72 \%)$ \\
\hline Other & $2(10 \%)$ & $6(10 \%)$ & $0 \quad(0 \%)$ & $16(14 \%)$ \\
\hline Length of hospital stay in days, mean $(S D)^{*}$ & $6.70(7.24)$ & $2.89(1.86)$ & $1.60(0.63)$ & $1.63(1.08)$ \\
\hline NISS total, mean $(S D)^{*}$ & $12.47(8.57)$ & $15.08(7.81)$ & $7.40(5.87)$ & $7.04(2.66)$ \\
\hline NISS non-head- related, mean $(S D)^{*}$ & $1.24(2.11)$ & $2.44(5.25)$ & $1.60(2.53)$ & $7.04(2.66)$ \\
\hline Lowest GCS score, mean $(S D)^{*}$ & $3.95(1.79)$ & $13.45(2.00)$ & $13.60(0.51)$ & - \\
\hline \multicolumn{5}{|l|}{ Neuroimaging abnormalities, $n(\%) *$ b } \\
\hline Absent & $7 / 19(37 \%)$ & $12 / 63(19 \%)$ & $15 / 15(100 \%)$ & $117 / 117(100 \%)$ \\
\hline Mild & $2 / 19(11 \%)$ & $14 / 63(22 \%)$ & $0 / 15 \quad(0 \%)$ & $0 / 117 \quad(0 \%)$ \\
\hline Moderate & $2 / 19(11 \%)$ & $13 / 63(21 \%)$ & $0 / 15 \quad(0 \%)$ & $0 / 117$ \\
\hline Severe & $8 / 19(42 \%)$ & $24 / 63(38 \%)$ & $(0 \%)$ & $0 / 117$ \\
\hline \multicolumn{5}{|l|}{ Coma duration, $n(\%): *$} \\
\hline None & $0 \quad(0 \%)$ & $64(0 \%)$ & $15(100 \%)$ & $117(100 \%)$ \\
\hline$<24$ hours & $15(75 \%)$ & $0 \quad(0 \%)$ & $0 \quad(0 \%)$ & $0 \quad(0 \%)$ \\
\hline$\geq 24$ hours & $5(25 \%)$ & $0 \quad(0 \%)$ & $0 \quad(0 \%)$ & $(0 \%)$ \\
\hline
\end{tabular}

Note. $\mathrm{TBI}=$ traumatic brain injury; $\mathrm{OI}=$ orthopedic injury; $\mathrm{SD}=$ standard deviation; NISS $=$ New Injury Severity Score; GCS $=$ Glasgow Coma Scale. *Significant difference between groups at $p<.05$.

aInjuries due to "other" causes included those related to sports and recreation, rough-housing, and falling objects.

${ }^{b}$ See text for definition of severity of neuroimaging abnormality. Abnormality was absent in the mild TBI and OI groups by definition.

groups also differed in mean "non-head-injury" NISS, computed as the NISS minus the AIS for the head region. By virtue of selection criteria for children with OI, the severity of injuries to regions other than the head was higher in this group than in the TBI groups. The distribution of causes of injury for the TBI group were consistent with national trends for young children, with a substantial proportion of both the TBI and OI group sustaining injuries due to falls (Langlois et al., 2006). A significant group difference in cause of injury reflected higher rates of transportation-related injuries in the TBI groups compared with the OI group. Neuroimaging abnormalities were classified based on findings reported by radiologists (records available for all but two children). The four categories of abnormality were: no lesion; mild abnormalities, defined as a single subdural, subarachnoid, or epidural hemorrhage, or a single intraparenchymal lesion, contusion or hemorrhage; moderate abnormalities, defined as multifocal lesions without diffuse abnormality (i.e., no edema, mass effect, swelling, midline shift, volume loss, or diffuse axonal injury); and severe abnormalities, defined as any diffuse abnormality, with or without focal lesions. The categorization of neuroimaging was based on previous research relating outcomes of TBI to the presence versus absence and type of brain lesions (Bowen et al., 1997; Levin, 1995; Levin et al., 1992; Prasad et al., 2002). At the time of the postacute assessment, 4 children with severe TBI and 3 with moderate TBI were receiving anti- epilepsy drugs, one with mild TBI was receiving Adderall, and none of the children in the OI group was taking a prescription medication.

\section{Assessment Procedures}

Child and family assessments were conducted in tandem as part of a more comprehensive evaluation of the child and family that also included parent interviews, ratings of child behavior, and video-taped parent-child interactions. Administered by parent interview, the LISRES-A has satisfactory internal consistency and was used to assess interpersonal supports and stressors experienced by the caregiver in a variety of social domains (e.g., with family members, friends, coworkers). Child tests were administered in a fixed order, with three separate but overlapping test batteries given to children in the following age ranges: 3 years, 0 months to 3 years, 5 months; 3 years, 6 months to 5 years, 11 months; and 6 years, 0 months to 6 years, 11 months.

Table 3 lists the child assessment procedures, the age ranges of administration, and the scores used in analysis. To obtain a measure of general cognitive ability, we administered the core subtests needed to compute the General Conceptual Ability (GCA) score of the Differential Ability Scales (DAS; Elliott, 1990). Other standardized tests were used to assess performance in the domains of language, memory, spatial reasoning, and school readiness skills. Nonstandard- 
Table 3. Neuropsychological test battery

\begin{tabular}{|c|c|c|c|c|}
\hline Domain/Test & Description & Age range & $n$ & Score for analysis \\
\hline \multicolumn{5}{|l|}{ General ability: } \\
\hline DAS GCA (Elliott, 1990) & $\begin{array}{l}\text { Composite of general } \\
\text { cognitive ability }\end{array}$ & $3: 0-6: 11$ & 214 & Standard score \\
\hline \multicolumn{5}{|l|}{ Language: } \\
\hline $\begin{array}{l}\text { CASL Pragmatic Judgment } \\
\text { (Carrow-Woolfolk, 2000) }\end{array}$ & Social communication skills & $3: 0-6: 11$ & 211 & Standard score \\
\hline $\begin{array}{l}\text { NEPSY Verbal Fluency } \\
\quad \text { (Korkman et al., 1998) }\end{array}$ & $\begin{array}{l}\text { Generation of different } \\
\text { types of animals and foods/ } \\
\text { drinks as quickly as possible }\end{array}$ & $3: 0-6: 11$ & 207 & Scaled score \\
\hline DAS Verbal Comprehension & $\begin{array}{l}\text { Demonstration of under- } \\
\text { standing of oral instructions }\end{array}$ & $3: 0-5: 11$ & 159 & T score \\
\hline DAS Naming Vocabulary & $\begin{array}{l}\text { Naming real objects and } \\
\text { pictures }\end{array}$ & $3: 0-5: 11$ & 158 & T score \\
\hline \multicolumn{5}{|l|}{ Memory: } \\
\hline DAS Recognition of Pictures & $\begin{array}{l}\text { Identification of previously } \\
\text { seen objects from a display } \\
\text { that includes both target and } \\
\text { distractor pictures }\end{array}$ & $3: 0-6: 11$ & 211 & T score \\
\hline DAS Recall of Digits & $\begin{array}{l}\text { Repetition of increasingly } \\
\text { longer strings of digits }\end{array}$ & $3: 0-6: 11$ & 206 & T score \\
\hline $\begin{array}{l}\text { WJ-III Story Recall } \\
\text { (Woodcock et al., 2001) }\end{array}$ & $\begin{array}{l}\text { Immediate recall of a } \\
\text { series of brief stories }\end{array}$ & $3: 0-6: 11$ & 198 & Standard score \\
\hline CASL Sentence Memory & $\begin{array}{l}\text { Repetition of increasingly } \\
\text { longer sentences }\end{array}$ & $3: 0-6: 11$ & 205 & Scaled score \\
\hline \multicolumn{5}{|l|}{ Spatial reasoning: } \\
\hline DAS Pattern Construction & $\begin{array}{l}\text { Construction of block designs } \\
\text { from pictorial representations }\end{array}$ & $3: 6-6: 11$ & 189 & T score \\
\hline DAS Copying Designs & $\begin{array}{l}\text { Paper and pencil reproduction } \\
\text { of geometric figures }\end{array}$ & $3: 6-5: 11$ & 133 & T score \\
\hline DAS Picture Similarities & $\begin{array}{l}\text { Identification of pictures and } \\
\text { relationships between them }\end{array}$ & $3: 0-5: 11$ & 159 & T score \\
\hline \multicolumn{5}{|l|}{ Executive functioning: } \\
\hline $\begin{array}{c}\text { Delay of Gratification Task } \\
\text { (Kochanska et al., 2000) }\end{array}$ & $\begin{array}{l}\text { Inhibition of opening an } \\
\text { attractive gift for } 150 \text { seconds }\end{array}$ & $3: 0-6: 11$ & 204 & Contact (yes/no) \\
\hline $\begin{array}{l}\text { Delayed Alternation } \\
\quad \text { (Espy et al., 1999) }\end{array}$ & $\begin{array}{l}\text { Retrieval of a small reward } \\
\text { from under one of two cups, } \\
\text { with alternating placement }\end{array}$ & $3: 0-6: 11$ & 208 & $\begin{array}{l}\text { Age-standardized } \\
Z \text {-score of number } \\
\text { of correct alternations }\end{array}$ \\
\hline Shape School (Espy, 1997) & $\begin{array}{l}\text { Stroop-like task involving } \\
\text { color and shape naming }\end{array}$ & $3: 0-6: 11$ & $182-131$ & $\begin{array}{l}\text { Age-standardized } \\
Z \text {-scores of efficiency } \\
\text { (number correct/ } \\
\text { completion time) }\end{array}$ \\
\hline \multicolumn{5}{|l|}{ School readiness skills: } \\
\hline WJ-III Letter/Word Identification & $\begin{array}{l}\text { Oral decoding of visually- } \\
\text { presented words }\end{array}$ & $3: 0-6: 11$ & 207 & Standard score \\
\hline WJ-III Spelling & $\begin{array}{l}\text { Written production of orally- } \\
\text { presented words }\end{array}$ & $3: 0-6: 11$ & 206 & Standard score \\
\hline WJ-III Applied Problems & $\begin{array}{l}\text { Solving orally-presented math } \\
\text { word problems }\end{array}$ & $3: 0-6: 11$ & 208 & Standard score \\
\hline DAS Early Number Concepts & $\begin{array}{l}\text { Counting, magnitude compari- } \\
\text { son, and other elementary } \\
\text { number problems }\end{array}$ & $3: 6-5: 11$ & 138 & T score \\
\hline Bracken SRC (Bracken, 1998) & $\begin{array}{l}\text { Six-subtest composite of } \\
\text { academic readiness skills }\end{array}$ & $3: 0-6: 11$ & 216 & Standard score \\
\hline
\end{tabular}

Note. DAS $=$ Differential Abilities Scales $;$ GCA $=$ General Conceptual Ability $;$ CASL $=$ Comprehensive Assessment of Spoken Language $;$ NEPSY $=$ A Developmental Neuropsychological Assessment; WJ-III = Woodcock-Johnson Tests of Achievement, $3^{\text {rd }}$ Ed.; SCR = School Readiness Composite. Variations in sample size were related in large part to the applicability of some of the measures to only a subset of the 3- to 6-year-old age range. Less marked variations in sample size were also related to the inability of some children to complete select tests. Reasons for variation in sample size for the different Shape School conditions is related to the applicability of the Switch and Both conditions only to children age 4 years and older and the inability of some age-eligible children to grasp task demands. 
ized tests of executive function included the Delay of Gratification Task (Kochanska et al., 2000), Delayed Alternation (DA; Espy et al., 1999), and Shape School (Espy, 1997). Delay of Gratification requires the child to inhibit opening an attractive gift, with performance defined in terms of contact versus no contact with the gift. In DA, the child is asked to retrieve a reward (e.g., an M\&M or a Cheerio) hidden under one of two cups placed side by side. The contingency is then reversed with the reward hidden under the other cup. The child is not allowed to see where the reward is placed, but can learn to anticipate placement because the placement side is reversed after each correct response. Performance was defined in terms of number of consecutively correct alternations. Shape School is a Strooplike measure of self regulatory abilities in young children. In this task, the child is first taught to name cartoon "pupils" by their shapes or colors. The child is then asked to name the color of some pupils but not others. This test measures the ability to inhibit prepotent responses and the mental flexibility to switch between color and shape names according to learned rules. Conditions include Simple Naming, Inhibition, Switching, and Both (the latter referring to a condition in which both inhibition and set switching are required). An efficiency score was computed for each condition by dividing the number correct by completion time.

\section{Data Analysis}

Before analysis, raw scores on the outcome measures were converted to age-standardized scores using published norms. Because published norms were unavailable for DA and Shape School, age-expected scores on these tests were generated based on regression analysis of data from the OI group. Age-adjusted $z$ scores were computed for each measure by dividing the differences between each observed and agepredicted score by the standard error of the estimate. Potential influences of extreme scores on results were limited by truncating, or windsorizing, standard scores to within 3 standard deviations of the mean score (Tabachnick \& Fidell, 1989). Examination of the scores revealed acceptable distributions for all continuous measures.

Preliminary analysis revealed that primary caregiver education level and median census tract income were positively correlated with each other and with most neuropsychological outcomes. Socioeconomic status (SES) was thus defined as the mean of the sample $z$-scores for these two variables. Additional sociodemographic variables (e.g., parent marital status and occupation) were examined but were excluded after initial analyses failed to reveal associations with outcomes independent of parent education and census income.

Group comparisons on the continuous measures of outcome were made using analysis of covariance (ANCOVA). Group effects were defined by preplanned contrasts of each TBI group with the OI group. Covariates included SES, sex, and race (white/nonwhite), as justified by evidence for associations of these factors with cognitive abilities in chil- dren (McDermott, 1995). Time since injury was not considered as analysis failed to reveal associations with the performance of the TBI sample. Covariate-adjusted logistic analysis was used to examine group differences in odds of contact versus no contact on the Delayed Gratification Task, with age at assessment entered as an additional covariate in analysis of this measure.

To assess the dose-response relationship of TBI presence and severity with outcome, a set of secondary analyses examined the linear trend between degree of TBI (none or $0=$ OI; $1=$ mild TBI, $2=$ moderate TBI, and $3=$ severe TBI) and covariate-adjusted test scores. To further investigate the relation of injury severity to outcomes for the children with TBI, we conducted regression analyses of data from the three TBI groups combined. In these analyses, the GCS score and coma duration (none, $<24 \mathrm{hr}, \geq 24 \mathrm{hr}$ ) were entered (separately) into a hierarchical regression following entry of SES, race, and sex.

Regression analysis was also used to examine moderating effects of SES, LISRES-A stressors and resources scores, and age at injury on the group differences. To test for moderation, each of these factors was entered separately into a regression along with the TBI-OI group contrast terms and the interaction of each contrast with that factor. Models that included the covariates were used to subsequently examine the moderating effects of LISRES-A resources and stressors and age at injury. Moderating effects of race and sex were not examined due to small cell sizes for the severe and mild TBI groups. Logistic regression was conducted to investigate moderating effects on the Delayed Gratification Task, with age at assessment again included as an additional covariate.

The Holm's modification of Bonferroni procedure (Jaccard \& Guilamo-Ramos, 2002) was used to adjust for multiple comparisons within each test domain, with domainwise alpha set at .05. Because of the more experimental nature of measures in the executive function domain and the lack of published age standards, this adjustment was not applied to the measures in that domain. However, effect sizes were computed for all group contrasts, and only significant differences of at least medium effect size $(d=.5)$ were considered in interpreting results from the tests of executive function. Statistical power computations indicated that the study was adequate for detection of a medium effect size for the moderate TBI-OI group contrasts but under-powered for detection of an effect of this magnitude for the severe TBI-OI and mild TBI-OI group contrasts. These results suggest that only relatively large effects of severe or mild TBI were likely to reach levels of statistical significance.

\section{RESULTS}

\section{Group Differences}

As shown in Table 4, the severe TBI group had lower scores than the OI group on the GCA, all four memory tests, Pat- 
Table 4. Group comparisons on neuropsychological and school readiness measures

\begin{tabular}{|c|c|c|c|c|c|c|c|}
\hline \multirow[b]{3}{*}{ Domain/measure } & \multicolumn{7}{|c|}{ Group } \\
\hline & \multicolumn{2}{|c|}{ Severe TBI $(n=20)$} & \multicolumn{2}{|c|}{ Moderate TBI $(n=64)$} & \multicolumn{2}{|c|}{ Mild TBI $(n=15)$} & \multirow{2}{*}{$\frac{\mathrm{OI}(n=117)}{\operatorname{Adj} . \mathrm{M}(\mathrm{se})}$} \\
\hline & Adj. $M(s e)^{a}$ & $\mathrm{ES}^{\mathrm{b}}$ & Adj. M (se) & ES & Adj. M (se) & ES & \\
\hline General ability: $\mathrm{GCA}^{\mathrm{c} *}$ & $89.55(2.98)$ & 0.68 & $98.58(1.66)$ & 0.10 & $97.19(3.53)$ & 0.19 & $100.14(1.23)$ \\
\hline \multicolumn{8}{|l|}{ Language: } \\
\hline CASL Pragmatic Judgment ${ }^{c}$ & $104.44(3.06)$ & 0.01 & $99.70(1.62)$ & 0.34 & $96.73(3.42)$ & 0.56 & $104.33(1.20)$ \\
\hline NEPSY Verbal Fluency ${ }^{\mathrm{e}}$ & $8.28(0.66)$ & 0.29 & $8.49(0.37)$ & 0.21 & $7.58(0.82)$ & 0.53 & $9.11(0.27)$ \\
\hline DAS Verbal Comprehension ${ }^{\mathrm{d}}$ & $41.34(2.13)$ & 0.34 & $43.73(1.32)$ & 0.11 & $43.93(2.40)$ & 0.09 & $44.82(0.94)$ \\
\hline DAS Naming Vocabulary ${ }^{\mathrm{d}}$ & $49.24(2.25)$ & 0.22 & $50.88(1.40)$ & 0.06 & $51.99(2.54)$ & 0.04 & $51.60(0.99)$ \\
\hline \multicolumn{8}{|l|}{ Memory: } \\
\hline DAS Recognition of Pictures ${ }^{\mathrm{d} *}$ & $44.11(2.40)$ & 0.56 & $49.90(1.36)$ & 0.04 & $46.57(2.84)$ & 0.34 & $50.33(0.99)$ \\
\hline DAS Recall of Digits ${ }^{\mathrm{d} * \dagger}$ & $46.22(2.30)$ & 0.61 & $48.08(1.35)$ & 0.43 & $47.32(2.83)$ & 0.50 & $52.62(0.95)$ \\
\hline WJ-III Story Recallc* & $103.95(3.36)$ & 0.65 & $109.21(1.70)$ & 0.26 & $107.62(3.48)$ & 0.38 & $112.70(1.23)$ \\
\hline CASL Sentence Memory ${ }^{\mathrm{e} * \dagger}$ & $8.43(0.62)$ & 0.59 & $8.86(0.35)$ & 0.43 & $9.57(0.72)$ & 0.17 & $10.05(0.25)$ \\
\hline \multicolumn{8}{|l|}{ Spatial reasoning: } \\
\hline DAS Pattern Construction ${ }^{\mathrm{d} *}$ & $44.29(2.16)$ & 0.97 & $54.39(1.26)$ & 0.07 & $52.68(2.60)$ & 0.11 & $53.74(0.87)$ \\
\hline DAS Copying Designs ${ }^{\mathrm{d} *}$ & $41.83(1.99)$ & 0.63 & $48.69(1.36)$ & 0.15 & $50.62(2.47)$ & 0.37 & $47.35(0.91)$ \\
\hline DAS Picture Similarities ${ }^{\mathrm{d}}$ & $44.52(2.61)$ & 0.47 & $49.68(1.61)$ & 0.01 & $50.99(2.95)$ & 0.10 & $49.82(1.15)$ \\
\hline \multicolumn{8}{|l|}{ Executive function: } \\
\hline Gift Delay, no contact, n (\%) & $8(44 \%)$ & - & $23(38 \%)$ & - & $7(50 \%)$ & - & $32(29 \%)$ \\
\hline DA, consecutive alternations ${ }^{f}$ & $-0.02(0.24)$ & 0.01 & $0.13(0.13)$ & 0.14 & $0.12(0.27)$ & 0.13 & $0.02(0.10)$ \\
\hline \multicolumn{8}{|l|}{ Shape School efficiency ${ }^{\mathrm{f}}$ : } \\
\hline Simple Naming condition & $-0.54(0.25)$ & 0.51 & $-0.05(0.14)$ & 0.02 & $-0.57(0.28)$ & 0.53 & $-0.03(0.10)$ \\
\hline Inhibit condition & $-0.26(0.24)$ & 0.19 & $-0.19(0.13)$ & 0.12 & $-0.29(0.28)$ & 0.23 & $-0.07(0.09)$ \\
\hline Switch condition* & $-0.63(0.26)$ & 0.61 & $-0.38(0.14)$ & 0.35 & $-0.64(0.31)$ & 0.62 & $-0.07(0.10)$ \\
\hline Both condition*† & $-0.74(0.26)$ & 0.76 & $-0.41(0.15)$ & 0.40 & $-0.57(0.32)$ & 0.57 & $-0.04(0.10)$ \\
\hline \multicolumn{8}{|l|}{ School readiness skills: } \\
\hline WJ-III Letter/Word Identification ${ }^{c}$ & $103.83(3.62)$ & 0.06 & $103.69(2.01)$ & 0.07 & $107.27(4.19)$ & 0.15 & $104.87(1.46)$ \\
\hline WJ-III Spelling ${ }^{\mathrm{c}}$ & $95.42(2.95)$ & 0.29 & $98.30(1.63)$ & 0.06 & $100.11(3.29)$ & 0.07 & $99.14(1.21)$ \\
\hline WJ-III Applied Problems ${ }^{c}$ & $96.65(2.96)$ & 0.46 & $103.14(1.64)$ & 0.01 & $107.41(3.54)$ & 0.32 & $102.97(1.19)$ \\
\hline DAS Early Number Concepts ${ }^{\mathrm{d}, *}$ & $40.94(2.08)$ & 0.70 & $47.34(1.48)$ & 0.02 & $45.03(2.53)$ & 0.27 & $47.56(0.96)$ \\
\hline Bracken $\mathrm{SRC}^{\mathrm{c} *}$ & $93.63(3.09)$ & 0.73 & $100.47(1.71)$ & 0.29 & $104.64(3.53)$ & 0.03 & $105.03(1.27)$ \\
\hline
\end{tabular}

Note. Group sizes vary across tests depending on whether the procedures were appropriate for all or a portion of the 3-to 6-year-old age range. Abbreviations: TBI = traumatic brain injury; OI = orthopedic injury; Adj. $\mathrm{M}=$ covariate-adjusted mean; se = standard error; ES = effect size; DAS $=$ Differential Abilities Scales; GCA = General Conceptual Ability; CASL = Comprehensive Assessment of Spoken Language; NEPSY = A Developmental Neuropsychological Assessment; WJ-III = Woodcock-Johnson Tests of Achievement, $3^{\text {rd }}$ Ed.; SCR = School Readiness Composite; Bracken $\mathrm{SRC}=$ Bracken Basic Concept Scale School Readiness Composite

${ }^{a}$ Means are adjusted for effects of SES, sex, and race.

${ }^{b}$ Effect sizes defined by Cohen's $d$ : difference between estimated (covariate-adjusted) means/estimate of pooled within-group $S D$.

${ }^{\mathrm{c} S t a n d a r d}$ score.

${ }^{\mathrm{d}} \mathrm{T}$ score

eScaled score.

${ }^{\mathrm{f}} \mathrm{Age}$-standardized $Z$ score.

*Significant difference, severe TBI versus OI.

${ }^{\dagger}$ Significant difference, moderate TBI versus $\mathrm{OI}$.

tern Construction, Copying Designs, Early Number Concepts, and SRC. The moderate TBI group had lower scores than the OI group on Sentence Memory, Recall of Digits, and the Shape School Both condition. Many of the effect sizes for the severe TBI-OI group contrasts were of medium magnitude (Cohen's $d=.5-.8$ ), whereas most effects for the moderate TBI-OI group contrasts were small (Cohen's $d=.2-.5$ ). Effect sizes for several of the mild TBI-OI group contrasts were in the medium range and in the hypothesized direction despite a lack of statistical significance, with nonsignificant trends (unadjusted $p \mathrm{~s}<.1$ ) for Verbal Fluency,
Recall of Digits, and the Shape School Simple Naming and Switch conditions.

\section{Other Factors Related to Outcome}

According to results from the ANCOVAs, all three covariates accounted for unique variance in at least some outcomes. Higher SES was associated with better performance on all tests except for the Delayed Gratification Task, DA, and the Shape School Both condition. Whites scored higher than nonwhites on Verbal Comprehension, Naming Vocab- 
ulary, and the Shape School Both condition. Females outperformed males on the GCA, Pragmatic Judgment, Verbal Comprehension, Recognition of Pictures, Recall of Digits, Story Recall, Shape School Simple Naming and Inhibition conditions, and Spelling.

In regressions examining the effect of group along a continuum from OI to severe TBI, significant linear trend effects were found for GCA, Sentence Memory, Story Recall, Recall of Digits, Pattern Construction, Shape School Switch and Both conditions, Early Number Concepts, and SRC (all adjusted $p \mathrm{~s}<.05$ ). For each of these outcomes, scores decreased with increasing TBI severity. Regressions conducted on data from the children with TBI indicated that a lower GCS score predicted worse outcomes on GCA, Pattern Construction, Copying Designs Early Number Concepts, and SRC; and longer coma duration predicted worse outcomes on GCS, Pattern Construction, Copying Designs, and Early Number Concepts (all adjusted $p$ s $<.05$ ).

\section{Moderators of TBI Effects}

Lower SES was associated with more adverse effects of severe TBI on Naming Vocabulary, $B=9.46$ (3.39), adjusted $p<.05$; and increasing parent stressors were associated with more negative consequences of moderate TBI on Spelling, $B=-0.78(0.29)$, adjusted $p<.05$. Results failed to reveal moderating effects of parent resources or age at injury on any of the outcomes.

\section{DISCUSSION}

\section{Effects of TBI in Young Children}

Consistent with findings from past research on young children, the participants in this study with moderate to severe TBI performed more poorly than the OI group on a wide range of neuropsychological and achievement tests (Anderson \& Catroppa, 2005; Anderson et al., 1997, 1999, 2006; Ewing-Cobbs et al., 1989, 1997, 2004a,b). Compared with the OI group, children with severe TBI had poorer general cognitive ability as measured by the GCA and lower scores on tests of memory, spatial reasoning, executive function, and school readiness skills. The moderate TBI group performed more poorly than the OI group on tests of memory and executive function, but not in general ability. The moderate TBI-OI group contrasts had smaller effect sizes than the severe TBI-OI group contrasts, suggesting that children with moderate TBI group had more selective and less pronounced deficits than those with severe TBI. Specifically, visual-perceptual and memory skills were most clearly affected, and there was no evidence for effects of moderate TBI on what might be regarded as established language skills. The deficits observed in this group are consistent with past evidence of selective impairments in children with TBI and with expectations based on the brain regions most susceptible to insult in TBI (Anderson et al., 1997, 2005b, 2006; Donders \& Giroux, 2005; Ewing-Cobbs et al., 1997;
Levin \& Hanten, 2005; Yeates, 2000). The present findings do not, however, contraindicate effects of TBI on language functions not tapped by our test battery, such as discourse processing and inferencing (Chapman et al., 1998; Dennis \& Barnes, 2001; Dennis et al., 2001; Ewing-Cobbs \& Barnes, 2002; Morse et al., 1999).

Although none of the mild TBI-OI contrasts was significant, the lower mean scores of the mild TBI group corresponded to medium effects sizes for several measures (Verbal Fluency, Recall of Digits, and the Shape School Simple Naming and Switch conditions). Given the limited statistical power for detection of these effects, results are interpreted as offering tentative support for postacute cognitive effects of mild TBI. Previous studies have yielded inconsistent effects of mild TBI, with some studies demonstrating adverse consequences for cognition or achievement (Anderson et al., 2001; Dennis \& Barnes, 2001; Gronwall et al., 1997; Jaffe et al., 1992; McKinlay et al., 2002; Ponsford et al., 1999) and others not (Anderson et al., 1999, 2005b, 2006). In a study comparing children with mild to moderate TBI with children hospitalized for other injuries, Goldstrohm and Arffa (2005) found differences similar to ours, but they did not isolate the effects mild TBI. The consequences of such injuries may vary depending on when after TBI children are assessed and the criteria used to define mild injury (Bijur \& Haslum, 1995; Satz et al., 1997). We recruited children who were hospitalized for at least 1 day and had some impairment in consciousness as defined by a GCS score of 13 or 14. For this reason, our mild TBI group may have had more significant trauma than children discharged home from emergency departments or with GCS scores of 15 .

\section{Additional Evidence for Effects of Injury Severity}

As further evidence for a relationship between TBI severity and outcomes, scores on many of the same tests that discriminated the severe TBI and OI groups were linearly related to the degree of TBI. Tests of the linear trend across groupsfrom OI to mild, moderate, and severe TBI-demonstrated that TBI severity was associated with the Switch and Both conditions of Shape School, offering further evidence for negative consequences of TBI on executive function in young children. Analyses of the effects of GCS score and coma duration on outcomes within the TBI sample provided additional support for injury severity as a predictor of the cognitive and achievement outcomes of TBI in young children (Bowen et al., 1997; Foreman et al., 2007; Levin, 1995; Prasad et al., 2002).

\section{Noninjury Factors Related to Outcomes of TBI}

Consistent with another study of young children (Anderson et al., 2006), better performance on nearly all measures was associated with higher SES, and these associations did not 
vary by group. The finding of higher scores in girls than boys for the majority of the measures was unexpected given the general absence of sex differences in on our previous research on a school-age TBI cohort (Yeates et al., 2002). Gender differences in rates of developmental disorders or early language skills may help to explain this finding (Thompson et al., 2003). Alternatively, a male predilection for preinjury developmental problems may have been exacerbated in our sample if these disorders contributed more to risk of injury in boys than in girls.

The findings also documented moderating influences of noninjury factors on some of the group differences. In keeping with results of our previous study of older children with TBI (Taylor et al., 2002; Yeates et al., 1997), weaknesses in Naming Vocabulary in the severe TBI group were evident only at lower levels of SES, and weaknesses in Spelling in the moderate TBI group were found only at higher levels of parent stressors. Potential explanations for these findings are that these skills were not as well established in children from less advantaged backgrounds and thus more easily disrupted by TBI, or that fewer resources were available after injury to support postinjury recovery (Taylor et al., 2002). The fact that both measures entail knowledge-based skills is consistent with these interpretations.

Results did not reveal moderating effects of age at injury on outcomes of TBI. The lack of evidence for worse outcomes in younger children contrasts with results from previous studies that have examined TBI across wider age spans (Anderson et al., 2005a; Barnes et al., 1999; Dennis et al., 1995; Ewing-Cobbs \& Barnes, 2002; Levin et al., 1995; Verger et al., 2000) and suggests that outcomes may be less strongly related to age at injury during early childhood (Ewing-Cobbs et al., 1997). Alternatively, the impact of younger age at injury may become more pronounced with increasing time since injury (Anderson et al., 2000a,b; Ewing-Cobbs et al., 2004a).

\section{Limitations}

Despite measuring a wide range of skills and assessing outcomes of TBI relative to those of an orthopedic injury group, the study was limited in several respects. First, only clinical neuroimaging, in most instances CT scans, were available to determine the presence and nature of the brain insults in the TBI sample. Imaging methods with greater sensitivity to white matter damage and focal lesions would likely have provided information useful in enhancing prediction of variations in outcomes of TBI (Scheibel \& Levin, 1997; Wilde et al., 2006). Second, the mild and severe TBI groups were relatively small despite recruitment from multiple hospitals, and larger group sizes would have increased statistical power for detection of effects. Third, the lowest GCS score was used to define injury severity. This measure likely overestimated TBI severity in some of the children who were sedated and intubated, though past studies showed that efforts to remove this confound yielded little improvement in predictive validity (Foreman et al., 2007; Zafonte et al., 1996).
Finally, we failed to assess some important cognitive outcomes, such as speed of processing (Catroppa \& Anderson, 2005), and we examined individual test scores rather than multiple-indicator latent constructs. The latter approach would have allowed us to more clearly distinguish the skills most and least affected by TBI and reduced the probability of Type I error

\section{CONCLUSIONS AND IMPLICATIONS}

Study findings suggest several conclusions with respect to the postacute effects of TBI on young children, and provide a basis for formulating more specific hypotheses about how TBI affects young children:

1. Severe TBI sustained during early childhood can result in generalized cognitive impairment and deficits in school readiness skills. Furthermore, memory, spatial reasoning, and executive function may be more affected than some language skills.

2. Children with moderate TBI have more specific and less pronounced impairments than those with severe TBI.

3. Indices of TBI severity, including the GCS score and coma duration, are related to cognitive and school readiness skills.

4. Although age at injury is not related to most postacute effects of TBI on cognitive and school readiness skills, at least within the 3- to 6-year-old age range, further follow-up is needed to determine whether age-at-injury effects emerge with increasing time since injury.

5. Measures of environmental disadvantage predict lower scores on most tests in children with and without TBI but also amplify the effects of TBI on some tests.

The primary clinical implication of these findings is that young children with TBI are at risk for postacute deficits in cognition and school readiness skills and that measures used in this study, or similar ones, are sensitive to these deficits. Although generalized cognitive deficits may be present in more severely injured children, even those with less severe TBI may be at risk for weaknesses in memory and executive function. As early academic readiness skills appear to be compromised, children who have sustained a recent TBI may be vulnerable to learning difficulties as they begin formal academic instruction. Monitoring of cognitive and readiness skills is thus recommended relatively soon after hospital discharge. Based on research showing slow recovery and emerging deficits in this age group (Anderson et al., 2000a,b, 2004, 2006), ongoing follow-up is additionally advised. The pattern of deficits observed in the present TBI sample also provides clues as to potentially useful educational interventions. In view of weaknesses in nonverbal abilities and executive function, children who are experiencing new-onset learning problems after TBI may benefit from structured teaching methods. Similarly, memory deficits suggest that it may be useful to provide these children 
with memory cues, repeated presentations of materials, and opportunities to practice newly taught skills.

Another clinical implication of the findings is the need to consider both injury-related and environmental factors in assessing risks for adverse outcomes of TBI. Lower SES and higher TBI severity contributed independently to poorer performance on many of the tests, but lower SES and parent stressors also potentiated the negative effects of TBI on some outcomes. These results underscore the complexity of influences on the recovery process (Taylor, 2004).

Further research is required to better understand the consequences of the full range of TBI severity on young children's brain development, and how brain pathology maps onto neurobehavioral outcomes. Larger scale studies of outcome will also be required, especially in examining the consequences of mild TBI. Further research on this subset of children might explore factors contributing to the decision to hospitalize these children and track acute changes in cognitive functioning. Assuming that mild TBI results in residual deficits in only a minority of children with mild TBI (Bigler, 2008; Kirkwood et al., in press), the identification of ways to distinguish affected from unaffected individuals may be more helpful than studies of group differences. The development of age-appropriate tests that clarify the effects of TBI and study of the factors that contribute to skill development following injury will be essential in improving our capacity to identify and treat the negative consequences of TBI in young children. We are currently following the present cohort to determine the nature of changes in cognitive and achievement outcomes across time post injury, evaluate behavioral sequelae, and investigate the effects of family factors on outcomes.

\section{ACKNOWLEDGMENTS}

Supported by grant R01 HD42729 to Dr. Wade from NICHD, in part by USPHS NIH Grant no. M01 RR 08084, and by Trauma Research grants from the State of Ohio Emergency Medical Services. The authors wish to acknowledge the contributions of Christine Abraham, Andrea Beebe, Lori Bernard, Anne Birnbaum, Beth Bishop, Tammy Matecun, Karen Oberjohn, Elizabeth Roth, and Elizabeth Shaver in data collection and coding. We also thank Nori Minich for her assistance in data analysis. The Cincinnati Children's Medical Center Trauma Registry, Rainbow Pediatric Trauma Center, Rainbow Babies \& Children's Hospital, Columbus Children's Hospital Trauma Program, and MetroHealth Center Department of Pediatrics and Trauma Registry provided assistance with recruitment.

\section{REFERENCES}

Anderson, V. \& Catroppa, C. (2005). Recovery of executive skills following paediatric traumatic brain injury (TBI): A 2-year follow-up. Brain Injury, 19, 459-470.

Anderson, V.A., Catroppa, C., Dudgeon, P., Morse, S.A., Haritou, F., \& Rosenfeld, J.V. (2006). Understanding predictors of functional recovery and outcome 30 months following early childhood head injury. Neuropsychology, 20, 42-57.
Anderson, V.A., Catroppa, C., Morse, S.A., \& Haritou, F. (1999). Functional memory skills following traumatic brain injury in young children. Pediatric Rehabilitation, 3, 159-166.

Anderson, V.A., Catroppa, C., Morse, S., Haritou, F., \& Rosenfeld, J. (2000a). Recovery of intellectual ability following traumatic brain injury in childhood: Impact of injury severity and age at injury. Pediatric Neurosurgery, 32, 282-290.

Anderson, V.A., Catroppa, C., Morse, S., Haritou, F., \& Rosenfeld, J. (2001). Outcome from mild head injury in young children: A prospective study. Journal of Clinical and Experimental Neuropsychology, 23, 705-717.

Anderson, V.A., Catroppa, C., Morse, S., Haritou, F., \& Rosenfeld, J. (2005a). Functional plasticity or vulnerability after early brain injury? Pediatrics, 116, 1374-1382.

Anderson, V.A., Catroppa, C., Morse, S., Haritou, F., \& Rosenfeld, J. (2005b). Attentional and processing skills following traumatic brain injury in early childhood. Brain Injury, 19, 699-710.

Anderson, V.A., Catroppa, C., Rosenfeld, J., Haritou, F., \& Morse, S.A. (2000b). Recovery of memory function following traumatic brain injury in pre-school children. Brain Injury, 14, 679-692.

Anderson, V. \& Moore, C. (1995). Age at injury as a predictor of outcome following pediatric head injury: A longitudinal perspective. Child Neuropsychology, 1, 187-202.

Anderson, V.A., Morse, S.A., Catroppa, C., Haritou, F., \& Rosenfeld, J.V. (2004). Thirty month outcome from early childhood head injury: A prospective analysis of neurobehavioural recovery. Brain, 127, 2608-2620.

Anderson, V.A., Morse, S.A., Klug, G., Catroppa, C., Haritou, F., Rosenfeld, J.V., \& Pentland, L. (1997). Predicting recovery from head injury in young children: A prospective analysis. Journal of the International Neuropsychological Society, 3, 568-580.

Barnes, M.A., Dennis, M., \& Wilkinson, M. (1999). Reading after closed head injury in childhood: Effects on accuracy, fluency, and comprehension. Developmental Neuropsychology, 15, 1-24.

Bawden, H.G., Knights, R.M., \& Winogron, H.W. (1985). Speeded performance following head injury in children. Journal of Clinical and Experimental Neuropsychology, 7, 39-54.

Bigler, E.D. (2008). Neuropsychology and clinical neuroscience of persistent post-concussive syndrome. Journal of the International Neuropsychological Society, 14, 1-22.

Bijur, P.E. \& Haslum, M. (1995). Cognitive, behavioral, and motoric sequelae of mild head injury in a national birth cohort. In S. Broman \& M.E. Michel (Eds.), Traumatic head injury in children (pp. 147-164). New York: Oxford University Press.

Blair, C. (2002). School readiness: Integrating cognition and emotion in a neurobiological conceptualization of children's functioning at school entry. American Psychologist, 57, 111-127.

Bowen, J.M., Clark, E., Bigler, E.D., Gardner, M., Nilsson, D., Gooch, J., \& Pompa, J. (1997). Childhood traumatic brain injury: Neuropsychological status at the time of hospital discharge. Developmental Medicine and Child Neurology, 39, 17-25.

Bracken, B.A. (1998). Bracken Basic Concept Scale-Revised Examiner's Manual. San Antonio, TX: The Psychological Corporation.

Bronson, M. (2000). Self-Regulation in Early Childhood: Nature and Nurture. New York: Guilford.

Carrow-Woolfolk, E. (2000). Comprehensive Assessment of Spoken Language: Manual. Circle Pines, MN: American Guidance Service. 
Catroppa, C. \& Anderson, V. (2005). A prospective study of the recovery of attention from acute to 2 years following pediatric traumatic brain injury. Journal of the International Neuropsychological Society, 11, 84-98.

Chadwick, O., Rutter, M., Brown, G., Shaffer, D., \& Traub, M. (1981). A prospective study of children with head injuries: II. Cognitive sequelae. Psychological Medicine, 11, 49-61.

Chapman, S.B., Levin, H.S., Wanek, A., Weyrauch, J., \& Kufera, J. (1998). Discourse after closed head injury in young children. Brain and Language, 61, 420-449.

Dennis, M. \& Barnes, M.A. (2001). Comparison of literal, inferential, and intentional text comprehension in children with mild or severe closed head injury. Journal of Head Trauma Rehabilitation, 16, 456-468.

Dennis, M., Purvis, K., Barnes, M.A., Wilkinson, M., \& Winner, E. (2001). Understanding of literal truth, ironic criticism, and deceptive praise following childhood head injury. Brain and Language, 78, 1-16.

Dennis, M., Wilkinson, M., Koski, L., \& Humphreys, R.P. (1995). Attention deficits in the long term after childhood head injury. In S. Broman \& M.E. Michel (Eds.), Traumatic Head Injury in Children (pp. 165-187). New York: Oxford University Press.

Donders, J. (2001). Using a short form of the WISC-III: Sinful or smart? Child Neuropsychology, 7, 99-103.

Donders, J. \& Giroux, A. (2005). Discrepancies between the California Verbal Learning Test: Children's Version and the Children's Category Test after pediatric traumatic brain injury. Journal of the International Neuropsychological Society, 11, 386-391.

Elliott, C. (1990). DifferentialAbility Scales: Introductory and Technical Handbook. San Antonio, TX: Psychological Corporation.

Espy, K.A. (1997). The Shape School: Assessing executive function in preschool children. Developmental Neuropsychology, 13, 495-499.

Espy, K.A., Kaufman, P.M., McDiarmid, M.D., \& Glishy, M.L. (1999). Executive functioning in preschool children: Performance on the A-Not-B and other delayed response format tasks. Brain and Cognition, 41, 178-199.

Ewing-Cobbs, L. \& Barnes, M. (2002). Linguistic outcomes following traumatic brain injury in children. Seminars in Pediatric Neurology, 9, 209-217.

Ewing-Cobbs, L., Barnes, M., Fletcher, J.M., Levin, H.S., Swank, P.R., \& Song, J. (2004a). Modeling of longitudinal academic achievement scores after pediatric traumatic brain injury. Developmental Neuropsychology, 25, 107-133.

Ewing-Cobbs, L., Fletcher, J.M., Levin, H.S., Francis, D.J., Davidson, K., \& Miner, M.E. (1997). Longitudinal neuropsychological outcomes in infants and preschoolers with traumatic brain injury. Journal of the International Neuropsychological Society, 3, 581-591.

Ewing-Cobbs, L., Miner, M.E., Fletcher, J.M., \& Levin, H.S. (1989). Intellectual, motor, and language sequelae following closed head injury in infants and preschoolers. Journal of Pediatric Psychology, 14, 531-547.

Ewing-Cobbs, L., Prasad, M.R., Landry, S.H., Kramer, L., \& DeLeon, R. (2004b). Executive functions following traumatic brain injury in young children: A preliminary analysis. Developmental Neuropsychology, 26, 487-512.

Fay, G.C., Jaffe, K.M., Polissar, M.L., Liao, S., Rivara, J.B., \& Martin, K.M. (1994). Outcome of pediatric traumatic brain injury at three years: A cohort study. Archives of Physical Medicine and Rehabilitation, 75, 733-741.
Fletcher, J.M., Ewing-Cobbs, L., Francis, D.J., \& Levin, H.S. (1995). Variability in outcomes after traumatic brain injury in children: A developmental perspective. In S.H. Broman \& M.E. Michel (Eds.), Traumatic Head Injury in Children (pp. 3-21). New York: Oxford University Press.

Fletcher, J.M., Ewing-Cobbs, L., Miner, M., Levin, H., \& Eisenberg, H. (1990). Behavioral changes after closed head injury in children. Journal of Consulting and Clinical Psychology, 58, 93-98.

Foreman, B.P., Caesar, R.R., Parks, J., Madden, C., Gentilello, L.M., Shafi, S., Carlile, M.C., Harper, C.R., \& Diaz-Arrastia, R.R. (2007). Usefulness of the Abbreviated Injury Score and the Injury Severity Score in comparison to the Glasgow Coma Scale in predicting outcome after traumatic brain injury. The Journal of Trauma, 62, 946-950.

Goldstrohm, S.L. \& Arffa, S. (2005). Preschool children with mild to moderate traumatic brain injury: An exploration of immediate and post-acute morbidity. Archives of Clinical Neuropsychology, 20, 675-695.

Gotschall, C.S. (1993). Epidemiology of childhood injury. In M.R. Eichelberger (Ed.), Pediatric Trauma: Prevention, Acute Care, and Rehabilitation (pp. 16-19). St. Louis, MO: Mosby Yearbooks.

Gronwall, D., Wrightson, P., \& McGinn, V. (1997). Effect of mild head injury during the preschool years. Journal of the International Neuropsychological Society, 3, 592-597.

Jaccard, J. \& Guilamo-Ramos, V. (2002). Analysis of variance frameworks in clinical child and adolescent psychology: Issues and recommendations. Journal of Clinical Child and Adolescent Psychology, 31, 130-146.

Jaffe, K.M, Fay, G.C., Polissar, N.L., Martin, K.M., Shurtleff, H., Rivera, J.B., \& Winn, H.R. (1992). Severity of pediatric traumatic brain injury and early neurobehavioral outcome: A cohort study. American Academy of Physical Medicine and Rehabilitation, 73, 540-547.

Keenan, H.T., Hooper, S.R., Wetherington, C.E., Nocera, M., \& Runyan, D. (2007). Neurodevelopmental consequences of early traumatic brain injury in 3-year-old children. Pediatrics, 119 , e616-e623.

Kirkwood, M.W., Yeates, K.O., Taylor, H.G., Randolph, C, McCrea, M., \& Anderson, V.A. (in press). Management of pediatric mild traumatic brain injury: A neuropsychological review from injury through recovery. The Clinical Neuropsychologist.

Kochanska, G., Murray, K.T., \& Harlan, E.T. (2000). Effortful control in early childhood: Continuity and change, antecedents, and implications for social development. Developmental Psychology, 36, 220-232.

Korkman, M., Kirk, U., \& Kemp, S. (1998). NEPSY-A Developmental Neuropsychological Assessment. San Antonio, TX: The Psychological Corporation.

Kraus, J.F. (1995). Epidemiological features of brain injury in children: Occurrence, children at risk, causes and manner of injury, severity, and outcomes. In S.H. Broman \& M.E. Michell (Eds.), Traumatic Head Injury in Children (pp. 22-39). New York: Oxford University Press.

Langlois, J.A., Rutland-Brown, W., \& Thomas, K.E. (2006). Traumatic Brain Injury in the United States: Emergency Department Visits, Hospitalizations, and Deaths. Atlanta, GA: Centers for Disease Control and Prevention, National Center for Injury Prevention and Control.

Levin, H.S. (1995). Prediction of recovery from traumatic brain injury. Journal of Neurotrauma, 12, 913-922. 
Levin, H.S., Aldrich, E.F., Saydjari, C., Eisenberg, H.M., Foulkes, M.A., Bellefleur, M., Luerssen, T.G., Jane, J.A., Marmarou, A., Marshall, L.F., \& Young, H.F. (1992). Severe head injury in children: Experience of the Traumatic Coma Data Bank. Neurosurgery, 31, 435-444.

Levin, H.S., Ewing-Cobbs, L., \& Eisenberg, H.M. (1995). Neurobehavioral outcome of pediatric head injury. In S. Broman \& M.E. Michel (Eds.), Traumatic Head Injury in Children (pp. 70 94). New York: Oxford University Press.

Levin, H.S. \& Hanten, G. (2005). Executive functions after traumatic brain injury in children. Pediatric Neurology, 33, 79-93.

McDermott, P.A. (1995). Sex, race, class, and other demographics as explanations for children's ability and adjustment: A national appraisal. Journal of School Psychology, 33, 75-91.

McKinlay, A., Dalrymple-Alford, J.C., Horwood, L.J., \& Fergusson, D.M. (2002). Long term psychosocial outcomes after mild head injury in early childhood. Journal of Neurology, Neurosurgery, and Psychiatry, 73, 281-288.

Moos, R.H. \& Moos, B.S. (1994). Life Stressors and Social Resources Inventory: Adult Form Manual. Odessa, FL: Psychological Assessment Resources.

Morse, S., Haritou, F., Ong, K., Anderson, V., Catroppa, C., \& Rosenfeld, J. (1999). Early effects of traumatic brain injury on young children's language performance: A preliminary linguistic analysis. Pediatric Rehabilitation, 3, 139-148.

Osler, T., Bakker, S.P., \& Long, W.A. (1997). A modification of the injury severity score that both improves accuracy and simplifies scoring. Journal of Trauma, 43, 922-925.

Ponsford, J., Willmott, C., Rothwell, A., Cameron, P., Ayton, G., Nelms, R., Curran, G., \& Ng, K.T. (1999). Cognitive and behavioral outcome following mild traumatic brain injury in children. Journal of Head Trauma Rehabilitation, 14, 360-372.

Prasad, M.R., Ewing-Cobbs, L., Swank, P.R., \& Kramer, L. (2002). Predictors of outcome following traumatic brain injury in young children. Pediatric Neurosurgery, 36, 64-74.

Satz, P., Zaucha, K., McCleary, C., Light, R., Asarnow, R., \& Becker, D. (1997). Mild head injury in children and adolescents: A review of studies (1970-1995). Psychological Bulletin, 122, 107-131.

Scheibel, R.S. \& Levin, H.S. (1997). Frontal lobe dysfunction following closed head injury in children: Findings from neuropsychology and brain imaging. In N.A. Drasnegor, G.R. Lyon, \& P.S. Goldman-Rakic (Eds.), Development of Prefrontal Cortex: Evolution, Neurobiology, and Behavior (pp. 241-263). Baltimore: Paul H. Brookes.

Schwartz, L., Taylor, H.G., Drotar, D., Yeates, K.O., Wade, S.L., \& Stancin, T. (2003). Long-term behavior problems after pediatric traumatic brain injury: Prevalence, predictors, and correlates. Journal of Pediatric Psychology, 28, 251-264.

Stancin, T., Drotar, D., Taylor, H.G., Yeates, K.O., Wade, S.L., \& Minich, N.M. (2002). Health-related quality of life of children and adolescents after traumatic brain injury. Pediatrics, 109, E34.

Tabachnick, B.G. \& Fidell, L.S. (1989). Using Multivariate Statistics (2nd ed.). New York: Harper and Row.
Taylor, H.G. (2004). Research on outcomes of pediatric traumatic brain injury: Current advances and future directions. Developmental Neuropsychology, 25, 199-225.

Taylor, H.G. \& Alden, J. (1997). Age-related differences in outcomes following childhood brain insults: An introduction and overview. Journal of the International Neuropsychological Society, 3, 1-13.

Taylor, H.G., Yeates, K.O., Wade, S.L., Drotar, D., Klein, S.K., \& Stancin, T. (1999). Influences on first-year recovery from traumatic brain injury in children. Neuropsychology, 13, 76-89.

Taylor, H.G., Yeates, K.O., Wade, S.L., Drotar, D., Stancin, T., \& Minich, N. (2002). A prospective study of short- and long-term outcomes after traumatic brain injury in children: Behavior and achievement. Neuropsychology, 16, 15-27.

Teasdale, G. \& Jennett, B. (1974). Assessment of coma and impaired consciousness: A practical scale. Lancet, 2, 81-84.

Thompson, T., Caruso, M., \& Ellerbeck, K. (2003). Sex matters in autism and other developmental disabilities. Journal of Learning Disabilities, 7, 345-362.

Verger, K., Junque, C., Jurado, M.A., Tresserras, P., Bartumeus, F., Nogues, P, \& Poch, J.M. (2000). Age effects on long-term neuropsychological outcome in paediatric traumatic brain injury. Brain Injury, 14, 495-503.

Wetherington, C.E. \& Hooper, S.R. (2006). Preschool traumatic brain injury: A review for the early childhood special educator. Exceptionality, 12, 155-170.

Wilde, E.A., Chu, Z., Bigler, E.D., Hunter, J.V., Fearing, M.A., Hanten, G., Newsome, M.R., Scheibel, R.S., Li, X., \& Levin, H.S. (2006). Diffusion tensor imaging in the corpus callosum in children after moderate to severe traumatic brain injury. Journal of Neurotrauma, 23, 1412-1426.

Woodcock, R.W., McGrew, K.S., \& Mather, N. (2001). WoodcockJohnson III Tests of Achievement. Itasca, IL: Riverside.

Yeates, K.O. (2000). Pediatric closed-head injury. In K.O. Yeates, M.D. Ris, \& H.G. Taylor (Eds.), Pediatric Neuropsychology: Research, Theory, and Practice (pp. 92-116). New York: Guilford.

Yeates, K.O. \& Taylor, H.G. (1997). Predicting premorbid neuropsychological functioning following pediatric traumatic brain injury. Journal of Clinical and Experimental Neuropsychology, 19, 825-837.

Yeates, K.O., Taylor, H.G., Drotar, D., Wade, S.L., Klein, S., Stancin, T., \& Schatschneider, C. (1997). Pre-injury family environment as a determinant of recovery from traumatic brain injuries in school-age children. Journal of the International Neuropsychological Society, 3, 617-630.

Yeates, K.O., Taylor, H.G., Wade, S.L., Drotar, D., Stancin, T., \& Minich, N. (2002). A prospective study of short- and long-term neuropsychological outcomes after traumatic brain injury in children. Neuropsychology, 16, 514-523.

Zafonte, R.D., Hammond, F.M., Mann, N.R., Wood, D.L., Black, K.L., \& Millis, S.R. (1996). Relationship between Glasgow Coma Scale and functional outcome. American Journal of Physical Medicine \& Rehabilitation, 75, 364-369. 